\title{
ANESTESIOLOGIA
} www.sba.com.b

\section{Combined Spinal-Epidural Anesthesia with Epidural Volume Extension causes a Higher Level of Block than Single-Shot Spinal Anesthesia}

\author{
Canan Salman ${ }^{1}$, Nurten Kayacan* 2, Fatma Ertuğrul 2, Zekiye Bıgat ${ }^{2}$, Bilge Karslı ${ }^{2}$
}

1. Medical Park Hospital, Department of Anesthesiology and Reanimation, Antalya, Turkey

2. Akdeniz University, School of Medicine, Department of Anesthesiology and Reanimation, Antalya, Turkey

Received from Akdeniz University School of Medicine, Department of Anesthesiology and Reanimation Antalya-Turkey.

Submitted on April 24, 2012. Approved on June 4, 2012.

\author{
Keywords: \\ Anesthesia, Spinal, \\ Epidural; \\ Injections, Epidural; \\ Anesthetics, Local; \\ Bupivacaine/ \\ levobupivacaine; \\ Cesarean Section.
}

\begin{abstract}
Background and objectives: We evaluated the effects of epidural injection with levobupivacaine or serum physiologic, epidural volume extension (EVE), when using combined spinal-epidural anesthesia (CSEA) for cesarean delivery.

Methods: One-hundred and thirty-eight patients with a full-term pregnancy of 37-42 weeks that were scheduled for cesarean delivery were included. Group $1(n=48)$ received single-shot spinal anesthesia (SSS), group $2(n=45)$ received CSEA-EVE with saline, group 3 received CSEA-EVE with levobupivacaine. The characteristics of motor and sensory block, the effects on maternal hemodynamic changes and the effects on the newborn were compared.

Results: Time to reach maximum sensory block was significantly shorter in groups 3 than in group 1 and 2 ( $p<0.05)$. Two-segment regression time of sensory block was significantly shorter in group 1 , whereas it was significantly longer in group 3 than in group $2(p<0.05)$. Time to onset of motor block was significantly longer in group 1 than in groups 2 and $3(p<0.05)$. Time to reach maximum motor block was significantly shorter in group 3 than in groups 1 and 2 ( $p<0.05)$. Time to recovery of motor block was significantly longer in group 3 than in groups 1 and $2(p<0.05)$. The time to first analgesic was significantly longer in group $3(p<0.05)$.

Conclusions: Sufficient and rapid motor and sensory block was achieved in all the patients in the present study; however, motor and sensory block had faster onset, lasted longer, and was of a higher level in groups 2 and 3; these effects were more pronounced in the group 3.

๑ 2013 Sociedade Brasileira de Anestesiologia. Published by Elsevier Editora Ltda. All rights reserved.
\end{abstract}

\section{Introduction}

Combined spinal epidural anesthesia (CSEA) is the preferred method for cesarean delivery. The spinal component provides rapid onset of anesthesia and the drugs that are administered through the catheter placed in the epidural space maintain analgesia during the postoperative period ${ }^{1}$. The epidural volume extension (EVE) technique is a modification of CSEA in which the level of sensory analgesia obtained via subarachnoid block is increased by a small volume of saline or local anesthetic administered through the epidural catheter ${ }^{2-6}$. The level of sensory block obtained is not only related to

${ }^{*}$ Corresponding author: Akdeniz University School of Medicine, Department of Anesthesiology and Reanimation Antalya-TURKEY. Phone: +90.242.249 6238

E-mail: fertug@hotmail.com

ISSN/\$ - see front metter c 2013 Sociedade Brasileira de Anestesiologia. Published by Elsevier Editora Ltda. All rights reserved. 
the analgesic effect of the local anesthetic administered into the epidural space, but to the effect of the volume of the epidural solution causing cephalic movement of the local anesthetic in the subarachnoid space ${ }^{5,7-9}$.

Researchers have reported that epidural administration of saline increases the level of sensory block without altering the intensity of spinal anesthesia; however, epidural injection of plain bupivacaine caused more intense motor block of longer duration for sensory and motor block, as well as analgesia, when used for volume extension during cesarean delivery ${ }^{10}$. Another study reported that when saline was used for EVE, the level of the spinal block obtained using hyperbaric bupivacaine did not increase; however, the maximum level of sensory block increased significantly in spinal block obtained using plain bupivacaine ${ }^{11}$.

In the present study we hypothesized that, in comparison to single-shot spinal anesthesia (SSS), an increase might be observed in intrathecal local anesthetic distribution when CSEA is administered in combined EVE. The purpose is to assess whether we can achieve more potent and more rapid onset of anesthesia this way.

\section{Methods}

The study included patients that had cesarean delivery. The Ethical Committee of Akdeniz University approved this study and all the participants provided informed consent. In total, we included in this study 138 ASA I-II patients aged 18-40 years with a full-term pregnancy of 37-42 weeks that were scheduled for cesarean delivery. Exclusionary criteria included history of allergy to local anesthetics, diabetes mellitus, height $<155 \mathrm{~cm}$ or weight $>100 \mathrm{~kg}$, pre-eclampsia, placenta previa, fetal anomalies, fetal bradycardia, neurologic or psychiatric disorders. All patients received $1,000 \mathrm{~mL}$ of Ringer's lactated intravenously before spinal anesthesia. Patients were monitored for non-invasive blood pressure, ECG, and peripheral oxygen saturation. We evaluated fetal heart rate prior to anesthesia.

The patients were randomly assigned to one of three groups using sealed opaque envelopes: each envelope contained one of the three codes: SSS, CSEA-EVE with saline, and CSEA-EVE with levobupivacaine. Care providers in the labour room generated the random allocation sequence. Group 1 $(n=48)$ received SSS anesthesia; Group $2(n=45)$ received CSEA (EVE with $5 \mathrm{~mL}$ saline); Group $3(\mathrm{n}=45)$ received CSEA (EVE with $5 \mathrm{~mL}$ of $0.5 \%$ levobupivacaine).

In Group 1 (SSS), following identification of the L3-4 or L4-5 intervertebral space while in the right lateral recumbent position, the following doses of $0.5 \%$ levobupivacaine were injected in addition to $20 \mu \mathrm{g}$ of fentanyl over the course of 30 seconds using a $27 \mathrm{G}$ spinal needle (Quincke, Egemen, Izmir, Turkey): $10 \mathrm{mg}$ in patients with a height $\leq 160 \mathrm{~cm}, 12 \mathrm{mg}$ in those $161-164 \mathrm{~cm}$ in height, $14 \mathrm{mg}$ in those $165-169 \mathrm{~cm}$ in height, and $15 \mathrm{mg}$ in those with a height $\geq 170 \mathrm{~cm}$.

In Group 2 (CSEA-EVE with $5 \mathrm{~mL}$ saline), we identified the epidural space using an 18G Tuohy needle and performed dural puncture using a 27G spinal needle (Combifix, Egemen, Izmir, Turkey). Spinal anesthesia doses according to patient height in Group 2 were the same as described for Group 1, and a 20-G epidural catheter was inserted $4 \mathrm{~cm}$ into the epidural space. Five minutes after insertion of the epidural catheter, $5 \mathrm{~mL}$ of saline was administered through it for EVE.
In Group 3 (CSE-EVE with $5 \mathrm{~mL}$ of $0.5 \%$ levobupivacaine), after identification of epidural space, we performed dural puncture (Combifix, Egemen, Izmir, Turkey). Spinal anesthesia doses according to patient height in Group 3 were the same as described for Groups 1 and 2, and a 20G epidural catheter was inserted $4 \mathrm{~cm}$ into the epidural space. Five minutes after insertion of the epidural catheter, $5 \mathrm{~mL}$ of \% 0.5 levobupivacaine (Chirocaine, Abbott Laboratories, Istanbul, Turkey) was administered through it for EVE. Following the anesthetic procedure, all patients were placed in the supine position and their right hip was elevated with a pillow to prevent aortocaval pressure. We allowed surgery to proceed after a sensory height block of T4-5 was achieved.

To avoid inter-operator variability, the principal author performed all the blocks. At the end of each regional technique, an anesthesiologist who was unaware of the technique and drug received by each patient recorded hemodynamic status and block profile. Systolic blood pressure, diastolic blood pressure, mean blood pressure (MBP), heart rate, and oximetry $\left(\mathrm{SpO}_{2}\right)$ levels were periodically monitored during surgery. In order to evaluate the characteristics of the block, the Bromage scale was used for motor block $(0=$ normal motor function, 1 = loss of motor function at the hip, 2 = loss of motor function at the hip and knee, and $3=$ loss of motor function at the hip, knee, and ankle) and the pinprick test was used for sensory block. We recorded time to onset of sensory block, time for sensory block to reach T10, the level of maximum sensory block, time to reach maximum sensory block, 2 segment-regression time of sensory block, and regression of sensory block to T10 time to onset of motor block, time to reach maximum motor block, time to recover from motor block. We scored the quality of intraoperative anesthesia as follows: 0: unsuccessful block; 1: insufficient block (insufficient anesthesia, insufficient relaxation, need for adjuvant therapy, need for general anesthesia); 2: sufficient block. The need for the first postoperative analgesia was determined using the visual analogue scale (VAS), and the first analgesic was administered if the VAS score was $>3$.

We administered prophylactic ephedrine $5 \mathrm{mg}$ intravenously on all patients immediately following the anesthetic procedure in order to prevent hypotension. We administered an additional $5 \mathrm{mg}$ of ephedrine when blood pressure dropped to $20 \%$ below the baseline value, noting the total dosage. New-born were also noted Apgar scores ( $1^{\text {st }}$ and $\left.5^{\text {th }} \min \right)$.

We used SPSS (Statistical Package for Social Sciences) v.13.0 for Windows for statistical analysis of the obtained data. Quantitative data were analyzed using One-Way ANOVA. Qualitative data were analyzed using Pearson Chi-square test. Statistical significance was set at $p<0.05$. When aiming to detect a time to reach maximum sensory block, with a power $99.7 \%$, and $\alpha=0.05$, each group required a sample size of 45 .

\section{Results}

In total, we included in the study 138 patients that met the inclusion criteria. The 3 groups were compared in terms of demographic data, such as age, gestational age, height, weight, body mass index (BMI), and parity, but there were not any significant differences between the groups $(p>0.05)$ (Table 1). Inter-group comparison of block characteristics (Table 2) showed that time to onset of sensory block was 
Table 1 Patient characteristics.

\begin{tabular}{llll}
\hline & $\begin{array}{l}\text { Group 1 } \\
\text { SSS } \\
(\mathrm{n}=48)\end{array}$ & $\begin{array}{l}\text { Group 2 } \\
\text { CSE (EVE with saline) } \\
(\mathrm{n}=45)\end{array}$ & $\begin{array}{l}\text { Group 3 } \\
\text { CSE (EVE with } \\
\text { levobupivacaine } \\
(\mathrm{n}=45)\end{array}$ \\
\hline Age (years) & $31.02 \pm 5.02$ & $29.75 \pm 3.82$ & $29.35 \pm 4.98$ \\
Height $(\mathrm{cm})$ & $163.33 \pm 5.21$ & $162.15 \pm 6.85$ & $163.93 \pm 5.77$ \\
Weight $(\mathrm{kg})$ & $77.50 \pm 9.32$ & $76.24 \pm 10.87$ & $77.24 \pm 10.82$ \\
BMI $\left(\mathrm{kg} . \mathrm{m}^{-2}\right)$ & $29.02 \pm 3.38$ & $29.00 \pm 3.48$ & $28.66 \pm 3.65$ \\
Gestational age (weeks) & $37.70 \pm 1.33$ & $38.06 \pm 1.03$ & $37.91 \pm 1.04$ \\
Parity (\%) (primiparous/multiparous) & $54.2 / 45.8$ & $46.7 / 53.3$ & $44.4 / 55.6$ \\
\hline
\end{tabular}

Data are presented as mean \pm SD or $(\%)$.

Table 2 Blockade characteristics.

\begin{tabular}{|c|c|c|c|}
\hline & $\begin{array}{l}\text { Group } 1 \\
\text { SSS } \\
(n=48)\end{array}$ & $\begin{array}{l}\text { Group } 2 \\
\text { CSEA(EVE } \\
\text { with saline) } \\
(n=45)\end{array}$ & $\begin{array}{l}\text { Group } 3 \\
\text { CSEA(EVE with } \\
\text { levobupivacaine) } \\
(n=45)\end{array}$ \\
\hline Time to onset of sensory block(min) & $1.00 \pm 0.00$ & $1.00 \pm 0.00$ & $1.00 \pm 0.00$ \\
\hline Time to reach T10 level (min) & $1.81 \pm 1.06$ & $1.44 \pm 0.84^{*}$ & $1.00 \pm 0.00 * * \eta$ \\
\hline Maximum sensory block reached (\%) & $\begin{array}{l}79.17 \%(\mathrm{~T} 2-3) \\
20.83 \%(\mathrm{~T} 4-5)\end{array}$ & $\begin{array}{l}20 \%(\mathrm{~T} 1-2) \\
66.67 \%(\mathrm{~T} 2-3) \\
13.33 \%(\mathrm{~T} 4-5)\end{array}$ & $\begin{array}{l}37.78 \%(\mathrm{~T} 1-2) \\
66.22 \%(\mathrm{~T} 2-3)\end{array}$ \\
\hline Time to maximum sensory block (min) & $12.39 \pm 4.09$ & $10.95 \pm 4.28$ & $8.88 \pm 2.10 * * \eta$ \\
\hline Two segment-regression time of sensory block (min) & $65.16 \pm 11.72$ & $74.51 \pm 13.54^{*}$ & $88.33 \pm 10.28^{* *}$ q \\
\hline Time for sensory block to regress to $\mathrm{T} 10$ ( $\mathrm{min})$ & $131.27 \pm 16.98$ & $133.77 \pm 10.83$ & $158.66 \pm 15.52^{* *}$ ף \\
\hline Time to onset of motor block(min) & $1.20 \pm 0.61$ & $1.00 \pm 0.00^{*}$ & $1.00 \pm 0.00 * *$ \\
\hline Time to maximum motor block (min) & $4.87 \pm 2.20$ & $3.95 \pm 1.84^{*}$ & $3.04 \pm 0.29 * * 9$ \\
\hline Time for recovery for motor block (min) & $126.52 \pm 18.49$ & $129.88 \pm 12.01$ & $141.02 \pm 13.04 * *$ q \\
\hline
\end{tabular}

Data are presented as mean \pm SD or $(\%) .{ }^{*} \mathrm{p}<0.05$; significant differences between Group 1 and 2 ; ${ }^{* *} \mathrm{p}<0.05$; significant differences between Group 1 and 3; ๆ p < 0.05; significant differences between Groups 2 and 3.

similar in all 3 groups, whereas time for sensory block to reach T10 was significantly shorter in Group 3 (levobupivacaine was used for EVE) than in Groups 1 and $2(p<0.05)$. Time to reach maximum sensory block was significantly shorter in Groups 3 than in Group 1 and 2; the shortest time to reach maximum sensory block was observed in Group $3(p<0.05)$. Two-segment regression time of sensory block was significantly shorter in Group 1, whereas it was significantly longer in Group 3 than in Group 2 ( $\mathrm{p}<0.05$ ).

Time for sensory block to regress to T10 was significantly longer in Group 3 than in Groups 1 and 2. Maximum sensory block in Group 1 was at the T2-3 level in $79.17 \%$ of the patients, versus the T4-5 level in 20.83\%. In Group 2, maximum sensory block was at the T1-2 level in $20 \%$ of the patients, the T2-3 level in $66.67 \%$, and the T4-5 level in 13.33\%. In Group 3, maximum sensory block was at the T1-2 level in $37.78 \%$ of the patients and the T2-3 level in $66.22 \%$. Analysis of the quality of block showed that only 1 patient in Group 1 required fentanyl; sufficient block was achieved in all other patients and there was not a need for additional analgesics or sedatives.

Time to onset of motor block was significantly longer in Group 1 than in groups 2 and $3(p<0.05)$. Time to reach maximum motor block was significantly shorter in Group 3 than 
Table 3 Neonatal outcomes.

\begin{tabular}{llll}
\hline & $\begin{array}{l}\text { Group 1 } \\
\text { SSS } \\
(\mathrm{n}=48)\end{array}$ & $\begin{array}{l}\text { Group 2 } \\
\text { CSE -EVE with saline } \\
(\mathrm{n}=45)\end{array}$ & $\begin{array}{l}\text { Group 3 } \\
\text { CSE -EVE with 5 mL of 0.5\% } \\
\text { levobupivacaine } \\
(\mathrm{n}=45)\end{array}$ \\
\hline Apgar score at 1 min & $8.68 \pm 0.46$ & $8.71 \pm 0.45$ & $8.77 \pm 0.42$ \\
Apgar score at 5 min & $9.97 \pm 0.14$ & $9.95 \pm 0.20$ & $9.95 \pm 0.20$ \\
Weight of newborn $(\mathrm{gr})$ & $3,202.50 \pm 552.04$ & $3,297.60 \pm 439.98$ & $3,285.88 \pm 329.07$ \\
\hline Data are presented as mean \pm SD. & &
\end{tabular}

in groups 1 and $2(p<0.05)$. Time to recovery of motor block was significantly longer in Group 3 than in groups 1 and 2 ( $p<$ $0.05)$. There were not any statistically significant differences in MBP or heart rate when intraoperative hemodynamic data were considered between the groups $(P>0.05)$. None of the patients had bradycardia requiring atropine treatment. There was not a difference in patient need for additional ephedrine between the groups $(5.88 \pm 1.96 \mathrm{mg}$ in Group $1,5.38 \pm 1.38$ $\mathrm{mg}$ in Group 2, and $5.41 \pm 1.44 \mathrm{mg}$ in Group 3). Comparison of $1^{\text {st }}$ and $5^{\text {th }}$ minute APGAR scores in the new-borns showed that there was not a significant difference between the groups ( $p>0.05$ ) (Table 3$)$. The time to first analgesic was significantly longer in Group 3 than in Groups 1 and 2 ( $p<$ $0.05)(142.97 \pm 15.81 \mathrm{~min}$ in group $1,146.73 \pm 10.39 \mathrm{~min}$ in Group 2, and $163.35 \pm 12.91$ min in Group 3).

\section{Discussion}

The most important finding in the present study is that administration of CSEA and EVE with both saline and levobupivacaine resulted in faster onset and longer duration of sensory and motor block than SSS, even though the same dose of intrathecal local anesthetic was given. Using EVE with saline, small-dose spinal block can be extended to provide adequate anesthesia for cesarean delivery ${ }^{4}$. Several mechanisms were reported to play a role in the enhancement of spinal block by EVE with saline, including the volume effect, in which the theca is compressed by epidural saline, resulting in the squeezing of cerebrospinal fluid and more extensive spread of subarachnoid local anesthetic 5,6,8,12. This effect differs from the enhancement of block following EVE with local anesthetic, as saline extends the block height by a mechanical volume effect (that appears to be time-dependent) and does not prolong the duration of block. Beyond 30 minutes or after 2-segment regression has begun, EVE with saline has no effect on block extension and may even accelerate spinal block regression ${ }^{6,9}$.

Delayed administration of epidural saline beyond $10 \mathrm{mi}-$ nutes may have been the cause of frequent failure reported by Choi et al. ${ }^{10}$ when administering EVE and spinal block induced with $8 \mathrm{mg}$ of hyperbaric bupivacaine; the incidence of intraoperative pain exceeded $50 \%$. Bremerich et al. ${ }^{13}$ used $7.5,10$, and $12.5 \mathrm{mg}$ of hyperbaric $0.5 \%$ levobupivacaine in patients receiving spinal anesthesia for elective cesarean delivery. In all, $40 \%$ of their patients that received $7.5 \mathrm{mg}$ of levobupivacaine required additional intraoperative intravenous opioid analgesic, and motor block was not complete.
There were not any significant differences in sensory or motor characteristics between the patients that received $10 \mathrm{mg}$ and $12.5 \mathrm{mg}$ of levobupivacaine; however, postoperative duration of analgesia was longer in the patients that received $10 \mathrm{mg}$ and $12.5 \mathrm{mg}$ of levobupivacaine.

Celleno et al. ${ }^{14}$ studied the use of CSEA for cesarean delivery and concluded that the minimum dose of local anesthetic (levobupivacaine) administered to the spinal component must be $11.10 \mathrm{mg}$, whereas Parpaglioni et al. ${ }^{15}$ reported that it should be $10.58 \mathrm{mg}$. In the present study we administered $10-15 \mathrm{mg}$ of levobupivacaine, based on patient height, and achieved complete analgesia in all patients. There is no consensus on the mechanism of action of EVE in conjunction with CSEA. Blumgart et al. ${ }^{12}$ administered $10 \mathrm{~mL}$ of saline, $10 \mathrm{~mL}$ of bupivacaine, or $0.5 \mathrm{~mL}$ of saline (control group) after administration of local anesthetic into the epidural space. The level of sensory block was significantly higher in the groups that received $10 \mathrm{~mL}$ saline or $10 \mathrm{~mL}$ of bupivacaine through epidural catheter than in the control group, and there were not any significant differences in hemodynamic parameters or complications between the groups. In a similar study by Stienstra et al. ${ }^{16}$ patients were divided into 5 groups after administration of $10 \mathrm{mg}$ of bupivacaine into the epidural space. The patients received $10 \mathrm{~mL}$ of $0.25 \%$ bupivacaine, $5 \mathrm{~mL}$ of $0.25 \%$ bupivacaine, $10 \mathrm{~mL}$ of saline, $5 \mathrm{~mL}$ of saline, or nothing through epidural catheters. The increase in the level of sensory block was significantly higher in the patients that received $10 \mathrm{~mL}$ of $0.25 \%$ bupivacaine than in the other patients, and the level of maximum sensory block increased to $C_{8}$. The researchers concluded that the increase in the level of anesthesia was not only related to the volume of the agent administered into the epidural space, but also in part to the dose effect of the local anesthetic agent. Similarly, in our study anesthesia was achieved faster, reached a higher level, and lasted longer in the patients that received CSEA - EVE with saline or levobupivacaine (Groups 2 and 3, respectively) than in those that received SSS (Group 1); however, anesthesia was achieved faster, reached a higher level, and lasted longer in Group 3 than in Group 2. As such, we think that the dose effect of the anesthetic administered to the epidural space may have caused the observed increase in the level of anesthesia.

The level of the sensory block achieved with administration of local anesthetic into the epidural space following administration of intrathecal local anesthetic in CSEA is not only related to the analgesic effect of the local anesthetic 
solution, but also to the cephalic movement of the intrathecal local anesthetic due to the volume effect of the administered solution. Tokiguchi et al. ${ }^{8}$ studied CSEA in patients scheduled for elective surgery and administered $7.5 \mathrm{mg}$ of $3 \%$ hyperbaric bupivacaine into the subarachnoid space. They alocated the patients into two groups; the treatment group received $10 \mathrm{~mL}$ of $0.9 \%$ isotonic $\mathrm{NaCl}$ solution through the epidural catheter 10 minutes after administration of bupivacaine, and the control group received nothing additional through the epidural catheter. In the treatment group, the level of sensory block 15 and 20 minutes after the spinal anesthesia was significantly higher than in the control group.

EVE also increases the duration of anesthesia. In our study, the time to first need for analgesic was significantly longer in Group 3 than in Groups 1 and 2. Numerous studies report an increase in the level of sensory block with CSEA, even though no agents or saline were administered through the epidural catheter. Ithin et al. ${ }^{1}$ studied spinal anesthesia and CSEA using $10 \mathrm{mg}$ of $0.5 \%$ hyperbaric bupivacaine in patients that underwent cesarean delivery. The epidural space was identified with $2 \mathrm{~mL}$ of air in the CSEA group and an epidural catheter was not inserted after intrathecal injection. The maximum level of sensory block in the spinal anesthesia group was T2-4, versus C5-8 in the CSEA group; CSEA without use of an epidural catheter or administration of an epidural agent resulted in a higher level of sensory block than spinal anesthesia when similar doses to intrathecal local anesthetics were administered. The researchers reported that, even though negative pressure was maintained in the epidural space using spinal anesthesia, negative pressure in the epidural space was equalized to the atmospheric pressure via the epidural needle used for CSEA and dural sac volume decreased; hence, there was an increase in the level of sensory block after administration of the spinal dose of local anesthetic.

Goy et al. ${ }^{17}$ reported that the level of sensory block achieved using CSEA was 2 segments higher that that achieved using spinal anesthesia in patients that underwent minor gynecologic surgery. Lew et al. ${ }^{4}$ administered intrathecal spinal anesthesia ( $9 \mathrm{mg}$ of $0.5 \%$ bupivacaine and $10 \mu \mathrm{g}$ of fentanyl) only to one group, and administered CSEA (intrathecal $5 \mathrm{mg}$ of $0.5 \%$ bupivacaine and $10 \mu \mathrm{g}$ of fentanyl) to the other group, followed 5 minutes later with epidural $6 \mathrm{~mL}$ of $0.9 \%$ isotonic $\mathrm{NaCl}$ solution through the catheter. In both groups, the level of sensory block necessary for painless cesarean delivery $\left(T_{5}\right)$ was achieved; however, motor recovery was faster in the group that received $6 \mathrm{~mL}$ of $0.9 \%$ isotonic $\mathrm{NaCl}$ solution through the epidural catheter. Intergroup comparison showed that the time to first need for analgesic and VAS pain scores were similar in both groups. The researchers concluded that CSEA and EVE may decrease the anesthetic dose needed by $55 \%$, as well as enable sufficient anesthesia for elective caesarean delivery and facilitate a shorter stay in the recovery room due to its associated rapid motor recovery time.

Intrathecal levobupivacaine seems to have a lower potency for motor block than bupivacaine, but the ideal dose of intrathecal levobupivacaine for cesarean delivery remains uncertain ${ }^{18-20}$. Bouvet et al. ${ }^{21}$ reported that, when combined with opioids, $\mathrm{ED}_{95}$ of intrathecal levobupivacaine is $12.9 \mathrm{mg}$ for caesarean delivery. Gori et al. ${ }^{22}$ evaluated influence of positioning on $12.5 \mathrm{mg}$ plain levobupivacaine spinal anesthesia in cesarean section. In our study, the same spinal doses according to the patient height was administered to all the patients to ensure a sufficient level of anesthesia, especially in Group 1, and not to adversely influence the comfort of the patient during cesarean delivery.

Since the spinal is usually a single-shot technique, it is not possible to improve an inadequate block or provide extended post-operation pain relief. When we have a look at the studies regarding application duration and cost of SSS and CSEA techniques, Choi et al. compared CSEA versus SSS for cesarean section and concluded that anesthetic procedure time was significantly longer in CSEA group (CSEA: $4.6 \pm 1.6$ $\mathrm{min})$. Although time difference between the two techniques is considered statistically significant, in cases of elective cesarean section the CSEA technique can overcome the limits connected with the SSS technique ${ }^{23,24}$.

Edward et al. retrospectively reviewed the chars of patients who had received epidural or spinal anesthesia for non-emergent cesarean section. Their data supported that spinal anesthesia resulted in a shorter operating room time than epidural anesthesia did. Epidural block is inherently more time-consuming than a spinal block. In this study, spinal anesthesia is reported to be more cost effective than epidural anesthesia ${ }^{25}$.

Butwick et al. reported that there is increased use of a CSEA technique in morbidly obese patients (BMI $\geq 40$ $\left.\mathrm{kg} \cdot \mathrm{m}^{-2}\right)$, compared with non-obese patients undergoing elective cesarean delivery. The cost for the anesthesia kit used for neuraxial block placement was significantly higher in morbidly obese patients. In this study, a higher percentage of morbidly obese patients received a CSEA technique, which was associated with higher equipment costs than SSS anesthesia ${ }^{25}$.

Although the CSEA technique seems to be disadvantageous compared to the SSS anesthesia in terms of application duration and cost, its use for patients undergoing cesarean section is advantageous as it allows neuraxial blockade to be maintained (with additional doses of local anesthetic via the epidural catheter) after establishing adequate surgical anesthesia with a spinal technique ${ }^{24}$.

Choi et al. ${ }^{10}$ administered epidural $10 \mathrm{~mL}$ of saline or $10 \mathrm{~mL}$ of $0.25 \%$ bupivacaine 10 minutes after intrathecal injection of $8 \mathrm{mg}$ of $0.5 \%$ hyperbaric bupivacaine, and nothing was administered to the epidural space in the control group. They did not obtain a level of anesthesia satisfactory for surgery in the control group. EVE with saline increased the level of sensory block, but did not increase the quality of surgical anesthesia, whereas EVE with $10 \mathrm{~mL}$ of $0.25 \%$ bupivacaine did increase the quality of surgical anesthesia and supported postoperative block. The level of sensory block and muscle relaxation was similar in all the groups. They reported that the level of sensory block obtained via spinal anesthesia was so high that injection of $10 \mathrm{~mL}$ of epidural $0.25 \%$ bupivacaine had no effect. They also observed that the level of sensory block increased with saline injection; however, the efficacy of sensory block also increased when local anesthetic was administered. In our study none of the patients in Group 1 had sensory block at the T1-2 level; however, the maximum level of sensory block was at T1-2 in Groups 2 and 3. The number of patients that had sensory block at the T1-2 level was higher in Group 3. 
In conclusion, sufficient and rapid motor and sensory block was achieved in all the patients in the present study. However, motor and sensory block had faster onset, lasted longer, and was of a higher level in Groups 2 and 3; these effects were more pronounced in Group 3. We think that CSEA with EVE decreases the need for a spinal dose, and facilitates earlier onset of anesthesia and faster regression of spinal block due to low dosage, which results in faster mobilization.

\section{Acknowledgement}

This study was supported by a Grant from the Akdeniz University School of Medicine's Research and Application Centre (Project N $\circ$ 2007.04.0103.011).

\section{Conflict of interest}

No conflicts of interest were declared in relation to this article.

\section{References}

1. Ithnin F, Lim Y, Sia AT, Ocampo CE. Combined spinal epidural causes higher level of block than equivalent single-shot spinal anaesthesia in elective cesarean patients. Anesth Analg. 2006; 102:577-580.

2. Rawal N. Combined spinal-epidural anaesthesia. Curr Opin Anaesthesiol. 2005; 18:518-521.

3. Beale N, Evans B, Plaat F, Columb MO, Lyons G, Stocks GM. Effect of epidural volume extension on dose requirement of intrathecal hyperbaric bupivacaine at caesarean section. $\mathrm{Br} \mathrm{J}$ Anaesth. 2005;95:500-503.

4. Lew E, Yeo SW, Thomas E. Combined spinal-epidural anaesthesia using epidural volume extension leads to faster motor recovery after elective cesarean delivery: a prospective, randomized, double-blind study. Anesth Analg. 2004;98:810-814.

5. Stienstra R, Dahan A, Alhadi BZ, van Kleef JW, Burm AG. Mechanism of action of an epidural top-up in combined spinal epidural anaesthesia. Anesth Analg. 1996;83:382-386.

6. Mardirosoff $C$, Dumont L, Lemédioni $P$, Pauwels $P$, Massaut $J$. Sensory block extension during combined spinal and epidural. Reg Anesth Pain Med. 1998;23:92-95.

7. Cook TM. Combined spinal-epidural techniques. Anaesthesia. 2000;55:42-64.

8. Takiguchi T, Okano T, Egawa H, Okubo Y, Saito K, Kitajima T. The effect of epidural saline injection on analgesic level during combined spinal and epidural anaesthesia assessed clinically and myelographically. Anesth Analg. 1997;85:1097-1100.

9. Trautman WJ 3rd, Liu SS, Kopacz DJ. Comparison of lidocaine and saline for epidural top-up during combined spinal-epidural anaesthesia in volunteers. Anesth Analg. 1997;84:574-577.

10. Choi DH, Park NK, Cho HS, Hahm TS, Chung IS. Effects of epidural injection on spinal block during combined spinal and epidural anaesthesia for cesarean delivery. Reg Anesth Pain Med. 2000;25:591-595.
11. Tyagi A, Kumar A, Sethi AK, Mohta M. Epidural volume extension and intrathecal dose requirement: plain versus hyperbaric bupivacaine. Anesth Analg. 2008;107:333-338.

12. Blumgart $\mathrm{CH}$, Ryall $\mathrm{D}$, Dennison $B$, Thompson-Hill LM. Mechanism of extension of spinal anaesthesia by extradural injection of local anaesthetic. Br J Anaesth. 1992;69:457-460.

13. Bremerich DH, Kuschel S, Fetsch N, Zwissler B, Byhahn C, Meininger $D$. Levobupivacaine for parturients undergoing elective caesarean delivery. A dose-finding investigation. Anaesthesist. 2007;56:772-779.

14. Celleno D, Parpaglioni R, Frigo MG, Barbati G. Intrathecal levobupivacaine and ropivacaine for cesarean section. New perspectives. Minerva Anestesiol. 2005; 71:521-525.

15. Parpaglioni R, Frigo MG, Lemma A, Sebastiani M, Barbati G, Celleno D. Minimum local anaesthetic dose (MLAD) of intrathecal levobupivacaine and ropivacaine for caesarean section. Anaesthesia. 2006; 61:110-115.

16. Stienstra R, Dilrosun-Alhadi BZ, Dahan A, van Kleef JW, Veering BT, Burm AG. The epidural "top-up" in combined spinal-epidural anaesthesia: the effect of volume versus dose. Anesth Analg. 1999; 88:810-814.

17. Goy RW, Sia AT. Sensorimotor anaesthesia and hypotension after subarachnoid block: combined spinal-epidural versus single-shot spinal technique. Anesth Analg. 2004;98:491-496.

18. Camorcia M, Capogna G, Berritta C, Columb MO. The relative potencies for motor block after intrathecal ropivacaine, levobupivacaine, and bupivacaine. Anesth Analg. 2007;104:904907.

19. Gautier P, De Kock M, Huberty L, Demir T, Izydorczic M, Vanderick B. Comparison of the effects of intrathecal ropivacaine, levobupivacaine, and bupivacaine for caesarean section. $\mathrm{Br} \mathrm{J}$ Anaesth. 2003;91:684-689.

20. Bremerich DH, Fetsch N, Zwissler BC, Meininger D, Gogarten W, Byhahn C. Comparison of intrathecal bupivacaine and levobupivacaine combined with opioids for caesarean section. Curr Med Res Opin. 2007;23:3047-3054.

21. Bouvet $L, D a-C o l X$, Chassard $D$ et al. $E D_{50}$ and $E D_{95}$ of intrathecal levobupivacaine with opioids for caesarean delivery. $\mathrm{Br} \mathrm{J}$ Anaesth. 2011;106:215-220.

22. Gori F, Corradetti F, Cerotto V, Peduto VA. Influence of positioning on plain levobupivacaine spinal anaesthesia in caesarean section. Anesthesiol Res Pract. 2010; pii: 212696.

23. Choi DH, Ahn HJ, Kim JA. Combined low-dose spinal-epidural anesthesia versus single-shot spinal anesthesia for elective cesarean delivery. Int J Obstet Anesth. 2006;15:13-17.

24. Brizzi A, Greco F, Malvasi A, Valerio A, Martino V. Comparison of sequential combined spinal-epidural anesthesia and spinal anesthesia for cesarean section. Minerva Anestesiol. 2005;71:701-709.

25. Riley ET, Cohen SE, Macario A, Desai JB, Ratner EF. Spinal versus epidural anesthesia for cesarean section: a comparison of time efficiency, costs, charges, and complications. Anesth Analg. 1995;80:709-712. 